\title{
Transverse cervical vascular pedicle: It's extended use as 'second-line' recipient vessels in thoracic and upper arm reconstructions in addition to head-and-neck reconstructions
}

\author{
Srijana Muppireddy, Parvathi Ravula, Srikanth Rangachari, Najma Shaik, Sushma Maaturu \\ Department of Plastic and Reconstructive Surgery, Nizams Institute of Medical Sciences, Hyderabad, Telangana, India
}

Address for correspondence: Dr. Parvathi Ravula, Dr. Parvathi Ravula Addl. Professor, Department of Plastic and Reconstructive Surgery, Nizams Institute of Medical Sciences, Panjagutta, Hyderabad, Telangana - 500 082, India. E-mail: paaru_raavula@yahoo.co.in

\section{ABSTRACT}

Background: Selection of recipient vessels is one of the key factors for a successful microvascular reconstruction. Non-availability of primary recipient vessels in the vicinity necessitates surgeon to approach a remote second-line vascular access. Transverse cervical vessels (TCV) have been described as second-line vascular access for head-and-neck reconstructions. Due to its location, their use can be extended to the proximal chest and upper arm reconstructions. Aim: The aim of the study is to analyse the reliability of TCV as second-line recipient vessels for the upper arm and chest reconstructions in addition to the head-and-neck reconstructions. Materials and Methods: During 2010-2017, 14 TCV were explored as the choice of second-line recipient pedicle for specific indications. Clinical experience with different reconstructions discussed. Results: Out of 14 transverse cervical arteries, 13 were of adequate size for anastomosis. About 12 successful reconstructions were performed involving the head and neck (7), proximal thorax (3) and upper arm (2) for indications such as scarring from different aetiology (8), previous free flaps (2) and sacrificed vessels (2). In one case, the arterial anastomosis was shifted to superior thyroid artery. All the chest and upper arm reconstructions needed a realignment of the pedicle without any kink. Transverse cervical vein (TCV) could be used only 5/14 times either alone or along with external jugular vein (EJV). In other cases, EJV alone was used. All the 12 flaps survived without any vascular event. Conclusions: Transverse cervical vessels are reliable second-line recipient vessels in the head and neck; in addition, they are of use in the upper arm and proximal chest defects.

\section{KEY WORDS:}

Chest and upper arm reconstructions; second-line recipient vessels; transverse cervical vessels

\begin{tabular}{|l|l|}
\hline \multicolumn{2}{|c|}{ Access this article online } \\
\hline Quick Response Code: & Website: \\
\hline & www.ijps.org \\
\cline { 2 - 2 } & Dol: \\
\hline
\end{tabular}

This is an open access journal, and articles are distributed under the terms of the Creative Commons Attribution-NonCommercial-ShareAlike 4.0 License, which allows others to remix, tweak, and build upon the work non-commercially, as long as appropriate credit is given and the new creations are licensed under the identical terms.

For reprints contact: reprints@medknow.com

How to cite this article: Muppireddy S, Ravula P, Rangachari S, Shaik N, Maaturu S. Transverse cervical vascular pedicle: It's extended use as 'second-line' recipient vessels in thoracic and upper arm reconstructions in addition to head-and-neck reconstructions. Indian J Plast Surg 2018;51:182-9. 


\section{INTRODUCTION}

or a successful microvascular reconstruction, $\checkmark$ selection of appropriate recipient vessels in the near vicinity is one of the key decisions. In situations where the local vascular access is not available on account of scarring of different aetiology or non-availability of the vessels, remote vascular access would be required..$^{[1-3]}$

Transverse cervical pedicle found at the base of the neck is one such option for head-and-neck reconstructions. Since the location is the junction area for the thorax and the upper arm, transverse cervical vessels can be considered for microvascular reconstruction of these regions. We discuss our experience with transverse cervical vessels as a second-line recipient pedicle for proximal chest and upper arm reconstructions in addition to the head-and-neck reconstructions.

\section{MATERIALS AND METHODS}

During the years 2010-2017, 14 transverse cervical vessels were explored for microvascular reconstructions involving head and neck, proximal chest and upper arm defects. Scarring consequent to previous surgery, radiation, trauma or burns precluded the choice of usual vessels.

Before the neck exploration, the course of the external jugular vein (EJV) was noted and marked. A sandbag under the shoulder permitted exposure of the posterior triangle of the neck. Exploratory incision was given along the lower third of lateral border of sternocleidomastoid then extending laterally in the supraclavicular area, about one inch above the upper border of the clavicle. Initially, the EJV was dissected and preserved. The omohyoid muscle running across the posterior triangle was the marker for the location of the transverse cervical vessels, which were explored in the underlying fat planes, above the omohyoid [Figure 1]. Proximal dissection of the artery stopped $1 \mathrm{~cm}$ lateral to the phrenic nerve; both the artery and venae commitantes were identified and checked for the adequacy of size and flow before proceeding with the reconstruction.

Pedicle was realigned for the chest and upper arm reconstructions according to the site of the defect. It was pivoted down in a smooth arc, for not $>90^{\circ}$. If the pedicle needed $>90^{\circ}$ adjustment, donor pedicle is pivoted to maintain a smooth arc to avoid kink at the anastomosis.

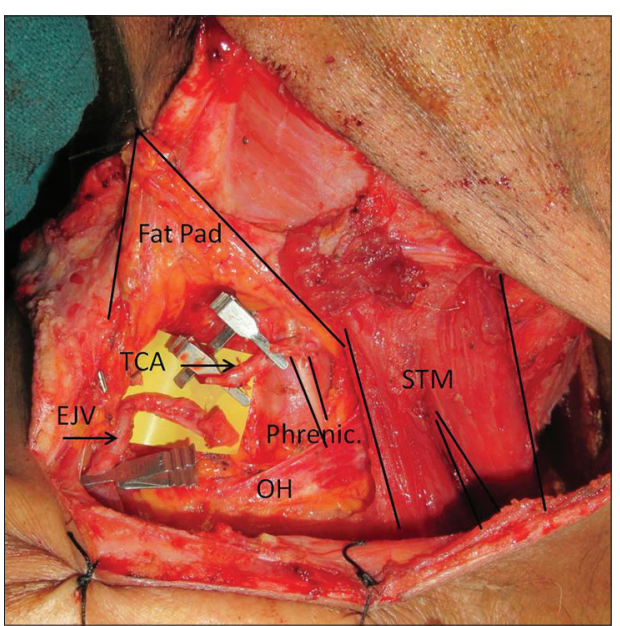

Figure 1: Anatomical landmarks for transverse cervical vessels - STM: Sternomastoid, OH: Omohyoid, TCa: Transverse cervical artery, EJV: External jugular vein

Available length of the recipient pedicle after the distal transection [Figure 2], vessel diameter and mismatch were noted.

About 12 reconstructions were performed. Risk of pedicle kink or redundancy, need for re-exploration, flap salvage, complications and ultimate flap outcome were analysed.

\section{RESULTS}

A total of 14 transverse cervical vessels were explored as second-line recipient vessels.

Age group ranged from 14 to 67 years, eight patients were male and six patients were female. Eight right side and six left side transverse cervical vessels were explored. Details of the indications, reconstructions and type of the flap used have been tabulated in [Table 1].

Indications included prior surgery and/or radiotherapy (RT) in five cases, post-traumatic scarring in two, post-electrical burn scarring in one case, previous microvascular reconstructions in two and sacrifice of vessel during the surgical clearance in two cases.

In two cases of hemifacial atrophy involving the proximal neck, there was a concern that the facial artery would be hypoplastic.

Different free flaps with variable donor vessel diameter were used for reconstructions, four anterolateral thigh (ALT), three fibulas, two tensor fascia lata (TFL) 


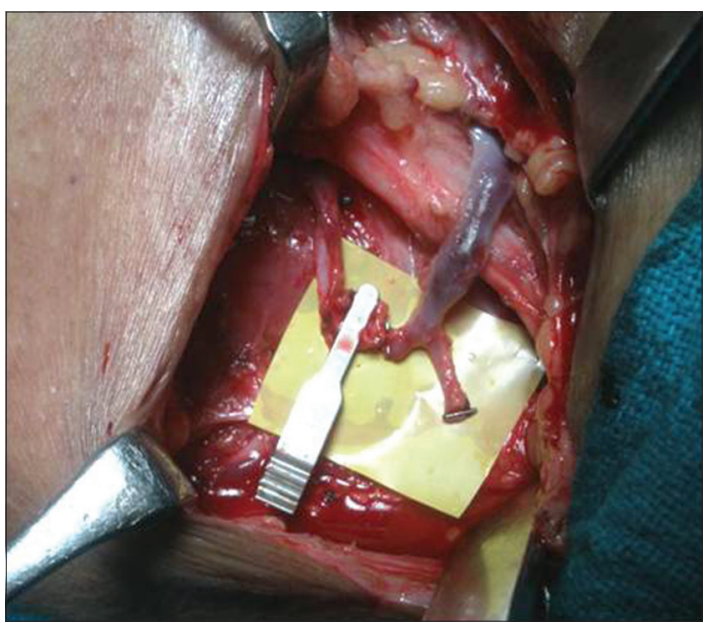

Figure 2: Transverse cervical arteries, on an average $3.4 \mathrm{~cm}$ of artery could be dissected

flaps, one radial forearm flap, one gracilis and one rectus femoris flap.

Transverse cervical vessels could be found in all the 14 explorations (100\%). An average of $3.4 \mathrm{~cm}$ usable length and a diameter of $>2 \mathrm{~mm}$ was available for arterial anastomosis (13/14 cases). In one case, vessels were smaller and could not be used.

There was not much of vessel mismatch with the donor vessels of ALT, TFL, rectus femoris and gracilis. There was about 1.5 times mismatch with the donor vessels of fibula and radial artery forearm flap which was acceptable for micro anastomosis.

About 12 successful reconstructions were performed using the transverse cervical artery, involving the head and neck (7), proximal chest (3) and upper arm defects (2).

Transverse cervical artery was not used in two cases of hemifacial atrophy involving the proximal neck, and the anastomosis was shifted to an alternative artery.

In one of these cases, repeated arterial thrombosis occurred on table, with the thrombus extending proximally (probably clamp induced intimal damage). Superior thyroid artery was used as an alternative artery [Figure 4]. In the other case, the transverse cervical vessels were smaller in size, and facial artery and EJV were used thus 12 transverse cervical arteries (TCa) were used for arterial anastomsis.

In all the explorations, accompanying veins were available. Indian Journal of Plastic Surgery Volume 51 Issue 2 May-August 2018

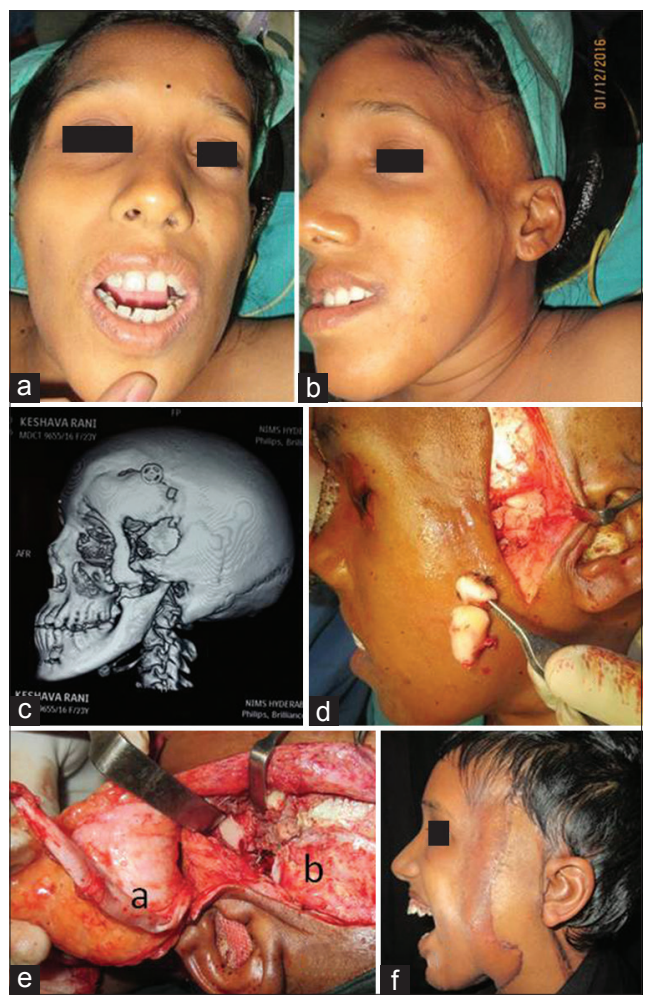

Figure 3: (a) Extra-articular left temporomandibular join ankylosis. (b) Contour deformity left temple. (c) X-ray postresection and radiotherapy for Ewing's sarcoma left temple region. (d) Condylectomy. (e) Free anterolateral thigh flap a - vascularised fascia, b - post-condylectomy defect. (f) Follow-up before skin paddle correction

Of the 12 reconstructions using TCa, EJV alone was used for venous drainage in eight cases (8/12); transverse cervical veins alone were used in two cases and both accompanying vein and EJV were used in other two cases.

In one case of hemifacial atrophy with hypoplastic EJV, one transverse cervical vein and rerouted cephalic vein were used for venous drainage [Figure 4]. Thus, only five venae commitantes were used in 14 explorations.

About seven head-and-neck reconstructions were performed [Table 1] involving the lower third face and neck in four cases, middle and upper thirds in other three cases. Flaps with long donor pedicles (RAFA, Fibula) were tunnelled subcutaneously to reach the transverse cervical pedicle; the flaps with short pedicle length and the flaps (TFL, Rectus femoris) intended to reach upper third face were brought down to the recipient vessels by laying open the lateral neck to avoid traction on the pedicle [Figure 3]. Excess skin flap that traversed along the neck was excised subsequently after 3 months and neck wound was closed primarily. Since the natural lie of the transverse cervical vessels is vertical, there was no need for realignment of the pedicle and the risk of acute kink and redundancy was minimal. 
Muppireddy, et al.: Second line recipient vessels for Thoracic and Upper Arm Reconstructions

Table 1: Various defects, indications, vessels and flaps used

\begin{tabular}{|c|c|c|c|c|c|}
\hline Region & Indication & Reconstruction/flap & Flap & Vessels & Reason \\
\hline \multirow[t]{3}{*}{ Thoracic } & $\begin{array}{l}\text { Failed colon transposition for } \\
\text { post-corrosive stricture }\end{array}$ & $\begin{array}{l}\text { Thoracic oesophageal } \\
\text { reconstruction }\end{array}$ & Tubed ALT & TCA, EJV & Post-surgery \\
\hline & $\begin{array}{l}\text { Ewing's sarcoma sternum and right } \\
\text { anterior chest wall }\end{array}$ & Sternal reconstruction & $\begin{array}{l}\text { Fibula } \\
\text { osteocutaneous flap }\end{array}$ & TCA, TCV, EJV & $\begin{array}{l}\text { Surgical } \\
\text { sacrifice }\end{array}$ \\
\hline & $\begin{array}{l}\text { Post-trauma defect of left axilla and } \\
\text { lateral chest wall with multiple rib } \\
\text { fractures }\end{array}$ & $\begin{array}{l}\text { Cover for left axillary } \\
\text { structures and lateral } \\
\text { chest wall }\end{array}$ & TFL flap & TCA, TCV, EJV & $\begin{array}{l}\text { Zone of trauma } \\
\text { and injured } \\
\text { vessels }\end{array}$ \\
\hline \multirow[t]{2}{*}{$\begin{array}{l}\text { Upper } \\
\text { arm }\end{array}$} & $\begin{array}{l}\text { Post-traumatic pan brachial plexus } \\
\text { injury with infraclavicular scar }\end{array}$ & $\begin{array}{l}\text { Free functioning } \\
\text { muscle transfer for } \\
\text { elbow flexion }\end{array}$ & Gracilis & TCA, EJV & $\begin{array}{l}\text { Traumatic scar } \\
\text { infraclavicular } \\
\text { area }\end{array}$ \\
\hline & $\begin{array}{l}\text { Post-resection and post-RT for } \\
\text { Ewing's sarcoma right humerus }\end{array}$ & $\begin{array}{l}\text { Head and proximal } \\
\text { shaft humerus } \\
\text { reconstruction }\end{array}$ & $\begin{array}{l}\text { Fibula } \\
\text { osteocutaneous flap }\end{array}$ & TCA, EJV & Post-RT \\
\hline \multirow[t]{9}{*}{$\begin{array}{l}\text { Head } \\
\text { and neck }\end{array}$} & $\begin{array}{l}\text { Post-RND and post-fibula } \\
\text { reconstruction of maxilla with contour } \\
\text { deformity right side of the neck }\end{array}$ & $\begin{array}{l}\text { Post-RND contour } \\
\text { correction right side } \\
\text { of neck }\end{array}$ & $\begin{array}{l}\text { Partially } \\
\text { deepithelialised ALT }\end{array}$ & TCA, TCV & $\begin{array}{l}\text { Post-surgery } \\
\text { previous flap }\end{array}$ \\
\hline & $\begin{array}{l}\text { Post-fibula reconstruction for } \\
\text { mandible with deficient lower lip hight }\end{array}$ & $\begin{array}{l}\text { Lower lip } \\
\text { reconstruction }\end{array}$ & $\begin{array}{l}\text { RAFA flap with } \\
\text { Palmaris longus }\end{array}$ & TCA, EJV & $\begin{array}{l}\text { Previous free } \\
\text { flap }\end{array}$ \\
\hline & $\begin{array}{l}\text { Post-radionecrosis and osteomyelitis } \\
\text { of right mastoid with trismus }\end{array}$ & $\begin{array}{l}\text { Cover for exposed } \\
\text { dura and transverse } \\
\text { sinus }\end{array}$ & Rectus femoris flap & TCA, TCV & Post-RT \\
\hline & Fibrosarcoma neck right side & $\begin{array}{l}\text { Cover for neck } \\
\text { defect (right) }\end{array}$ & Free ALT flap & TCA, EJV & $\begin{array}{l}\text { Surgical } \\
\text { sacrifice }\end{array}$ \\
\hline & Post-RT left alveolar carcinoma & $\begin{array}{l}\text { Mandibular } \\
\text { reconstruction }\end{array}$ & $\begin{array}{l}\text { Fibula } \\
\text { osteocutaneous flap }\end{array}$ & TCA, EJV & Post-RT \\
\hline & $\begin{array}{l}\text { Post-electrical burn reconstruction of } \\
\text { left cheek with osteonecrosis of both } \\
\text { alveoli with infection and trismus }\end{array}$ & $\begin{array}{l}\text { Full-thickness cheek } \\
\text { reconstruction }\end{array}$ & Free TFL flap & TCA, EJV & $\begin{array}{l}\text { PEB scarring } n \\
\text { infection }\end{array}$ \\
\hline & $\begin{array}{l}\text { Post-resection, post-RT Ewing's } \\
\text { sarcoma left temple region with TMJ } \\
\text { ankylosis and contour deformity }\end{array}$ & $\begin{array}{l}\text { Release of left } \\
\text { TMJ ankylosis } \\
\text { and vascularised } \\
\text { fascia interposition } \\
\text { arthroplasty }\end{array}$ & Free ALT flap & TCA, EJV & Post-RT \\
\hline & $\begin{array}{l}\text { Failed fat grafting for right hemifacial } \\
\text { atrophy }\end{array}$ & Contour correction & $\begin{array}{l}\text { De epithelialised } \\
\text { ALT flap }\end{array}$ & $\begin{array}{l}\text { TCA - STA, TCV, } \\
\text { Cephalic vein }\end{array}$ & $\begin{array}{l}\text { Proximal neck } \\
\text { involvement, } \\
\text { EJV hypoplastic }\end{array}$ \\
\hline & Right hemifacial atrophy & Contour correction & $\begin{array}{l}\text { De epitheliaised ALT } \\
\text { flap }\end{array}$ & $\begin{array}{l}\text { Facial A, TCV } \\
\text { smaller in size }\end{array}$ & $\begin{array}{l}\text { Proximal neck } \\
\text { involvement }\end{array}$ \\
\hline
\end{tabular}

RT: Radiotherapy, TCA: Transverse cervical artery, TCV: Transverse cervical vein, EJV: External jugular vein, RAFA: Radial artery forearm flap, ALT: Anterolateral thigh flap, TFL: Tensor fascia lata flap, RND: Radical neck dissection, STA: Superior thyroid artery

All the upper limb and chest reconstructions needed a realignment of the recipient pedicle by carefully pivoting down the vessels for not $>90^{\circ}$.

If the required angulation was more and adequate donor pedicle length was available the donor pedicle was pivoted in a smooth arc.

All the transverse cervical vessels sustained the realignment of vessels very well without any problem of acute kinking or redundancy.

\section{Case details of the proximal chest and upper arm reconstructions}

1. Two-stage thoracic oesophageal reconstruction was done in a case of corrosive stricture, following a failed colon conduit. Cervical oesophageal fistula was situated on the left side of the neck; hence, the right-sided transverse cervical vessels were chosen as the choice of recipient pedicle. Free ALT flap of size $30 \mathrm{~cm} \times 10 \mathrm{~cm}$ was tubed on its cutaneous surface and tunnelled under the subcutaneous plane to the left side of the neck; donor pedicle was tunnelled across the lower neck on to the right side. TCa was pivoted down laterally about $60^{\circ}$ and donor vessels about $30^{\circ}$ upward with a gentle curve for microanastomosis. Proximal oesophageal anastomosis was done on the left side of the neck. Distal end of the tube was left as a cutaneous fistula at the xiphisternum. Second-stage restoration of distal bowel continuity was performed after 3 months [Figure 5]

2. Sternal reconstruction was performed for a case of Ewing's sarcoma. Defect involved total loss of sternum 


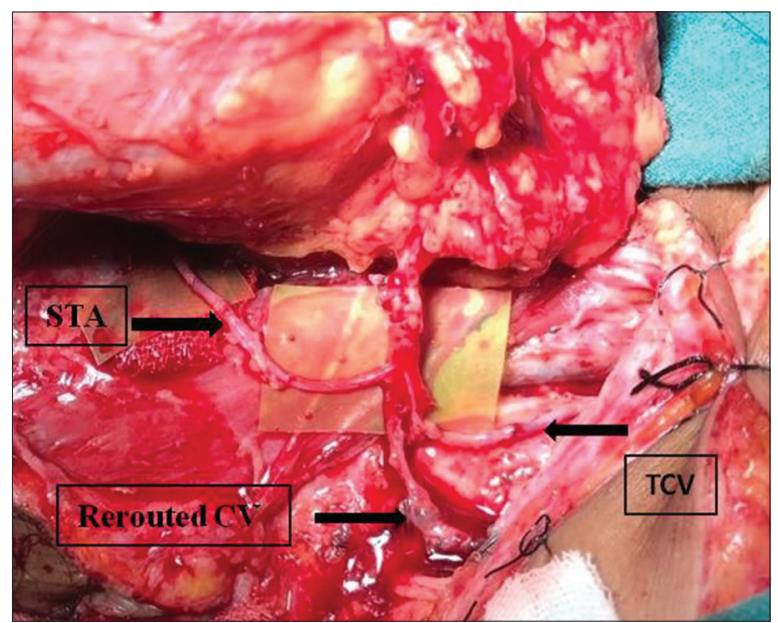

Figure 4: Anastomotic details in a case of hemifacial atrophy, Repeated arterial thrombosis occurred in transverse cervical artery, STA: Superior thyroid artery, CV: Cephalic vein and TCv: Transverse cervical vein were used

from the sternoclavicular joints on both the sides along with the right anterior chest wall extending up to the $5^{\text {th }}$ rib. During resection, the right internal mammary artery had been sacrificed. Free osteocutaneous fibula was used in a 'reverse 7 ' shape $(3 \mathrm{~cm}$ and $7 \mathrm{~cm}$ segments), stabilised at both the sternoclavicular joints and across the right first and left $3^{\text {rd }}$ ribs using titanium plates. Donor (peroneal) vessels were taken up into the neck and then pivoted down about $60^{\circ}$; the left TCa pivoted $20^{\circ}$ medially to make a smooth arc for the anastomosis [Figure 6]

3. Post-traumatic defect of the axilla and lateral chest wall with loss of latissimus dorsi, pectoralis major and multiple rib fractures extending from $2^{\text {nd }}$ rib and axillary artery repair, was reconstructed using free TFL flap. The left TCa was used after pivoting the artery about $45^{\circ}$ downwards laterally

4. Proximal humerus reconstruction was performed for a case of Ewing's sarcoma involving the head and proximal shaft, following resection and RT. Free osteocutaneous fibula flap of $13 \mathrm{~cm}$ length was used to stabilise the functioning forearm. The right transverse cervical artery was pivoted down about $40^{\circ}$ laterally and used as the recipient vessel [Figure 7]

5. One patient with pan brachial plexus injury underwent functioning muscle transfer using gracilis to restore the elbow function on account of infraclavicular scar, using the right TCa above the level of clavicle after pivoting the vessel down about $50^{\circ}$ laterally.

In 12 of 14 cases where the transverse cervical artery was used, there were no re-explorations. There were only two partial flap necroses; due to tight suturing in one
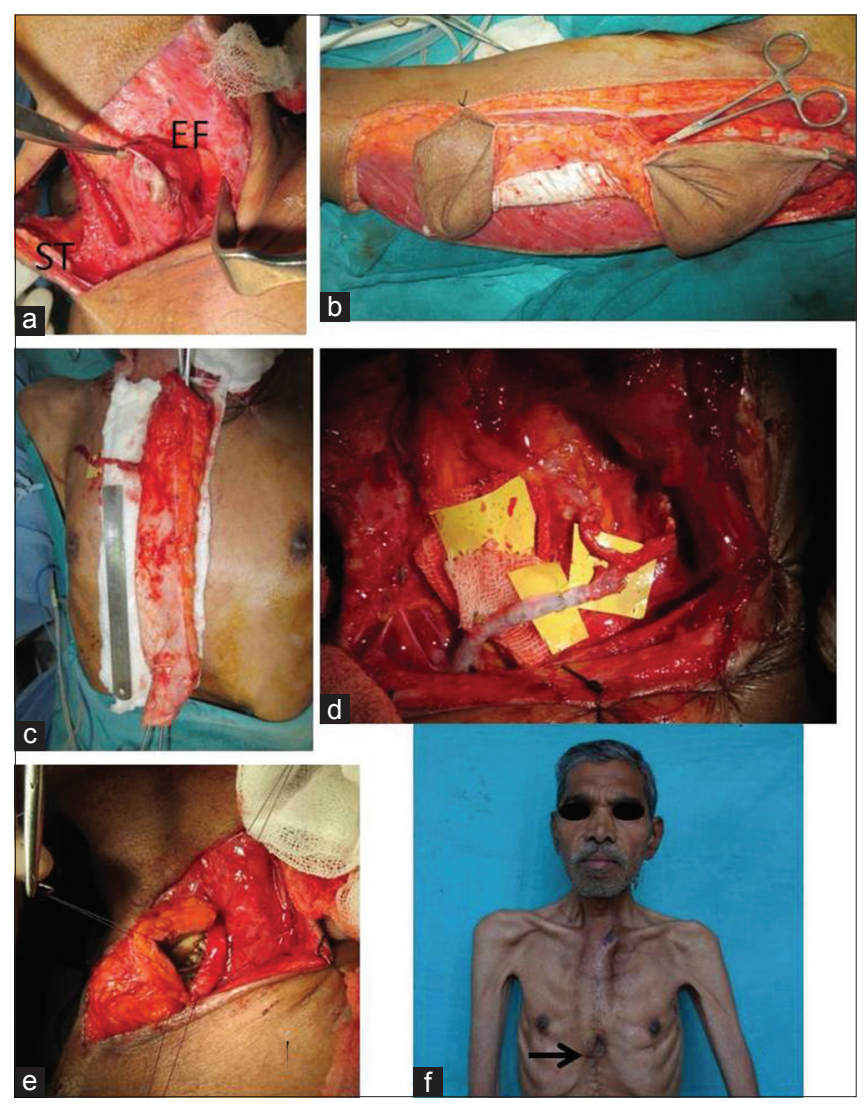

Figure 5: First-stage reconstruction of thoracic oesophagus for corrosive poisoning using tubed anterolateral thigh. (a) Left-sided oesophageal fistula - EF, ST - subcutaneous tunnel, (b and c) Tubing of anterolateral thigh, in its anatomical location, (d) Anastomosis after pivoting down the vessels with a smooth arc, (e) Anterolateral thigh and oesophageal anastomosis, (f) distal fistula

case, needed excision and split skin grafting. In the other case, the distal, most part of the fibula skin paddle, was necrosed; excision and primary closure were done before discharging the patient.

\section{DISCUSSION}

Selection of the recipient pedicle for a microvascular reconstruction is mainly based on the location of the defect and the proximity of recipient vessels. Factors such as quality of the vessels, the zone of injury, matching diameters of donor and recipient vessels, ease and safety of dissection and distance from the defect intended to be repaired (to avoid vein grafting) ${ }^{[4]}$ will also influence the selection the vessels.

Atherosclerosis and local factors such as prior radiation $^{[1,5-8]}$ and prior operative procedures influence the quality of the vessels and subsequent outcome of the procedure; ${ }^{[3,9-11]}$ the length of the vascular pedicle $e^{[12-15]}$ is also an important consideration. 


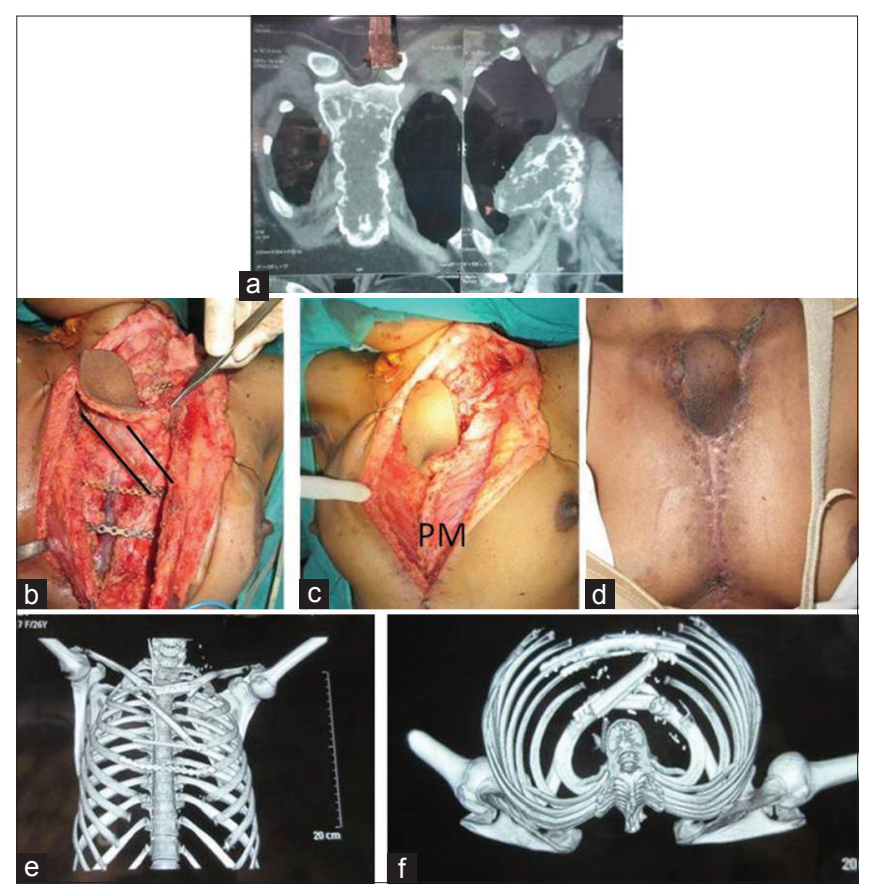

Figure 6: Sternal reconstruction using Fibula in 'Reverse 7' shape, (a) Computed tomography scan showing the sterna involvement, (b) Free osteocutaneous fibula reconstruction, oblique segment highlighted, (c) Recon plate across $4^{\text {th }}$ Rib covered by bilateral pectoralis major -PM, (d) 6 months follow-up, (e and f) three-dimensional computed tomography of the chest

Even when multiple recipient vessels are available for a given defect, usually one vessel will offer the most straightforward and safe option. However, in circumstances where the usual local vessels are not available, remote vascular access would be required. ${ }^{[1-3]}$

Options for primary recipient vessels varies region wise. Fortunately, multiple primary recipient vessels are available in head-and-neck region including (from cephalic to caudal) superficial temporal vessels, facial, lingual, superior thyroid and the transverse cervical. ${ }^{[16]}$ The $1^{\text {st }}$ four vessels are used much of the time depending on the location of the defect. ${ }^{[4,16,17]}$

If these primary vessels are not available for a safe anastomosis, alternative options include end-to-side anastomosis to the external carotid artery (ECA) or use of vessels from the contralateral neck directly or by using vein grafts. Even arteries outside of the neck such as internal mammary vessels and reverse flow thoraco dorsal scapular artery. ${ }^{[2,4,13,16]}$ also have been described. This makes the reconstruction complex and increases the risks incurred by using vein grafts. . $4,7,8,14,18,19]^{2}$

Transverse cervical vessels in the posterior triangle of the neck have been described as second-line recipient

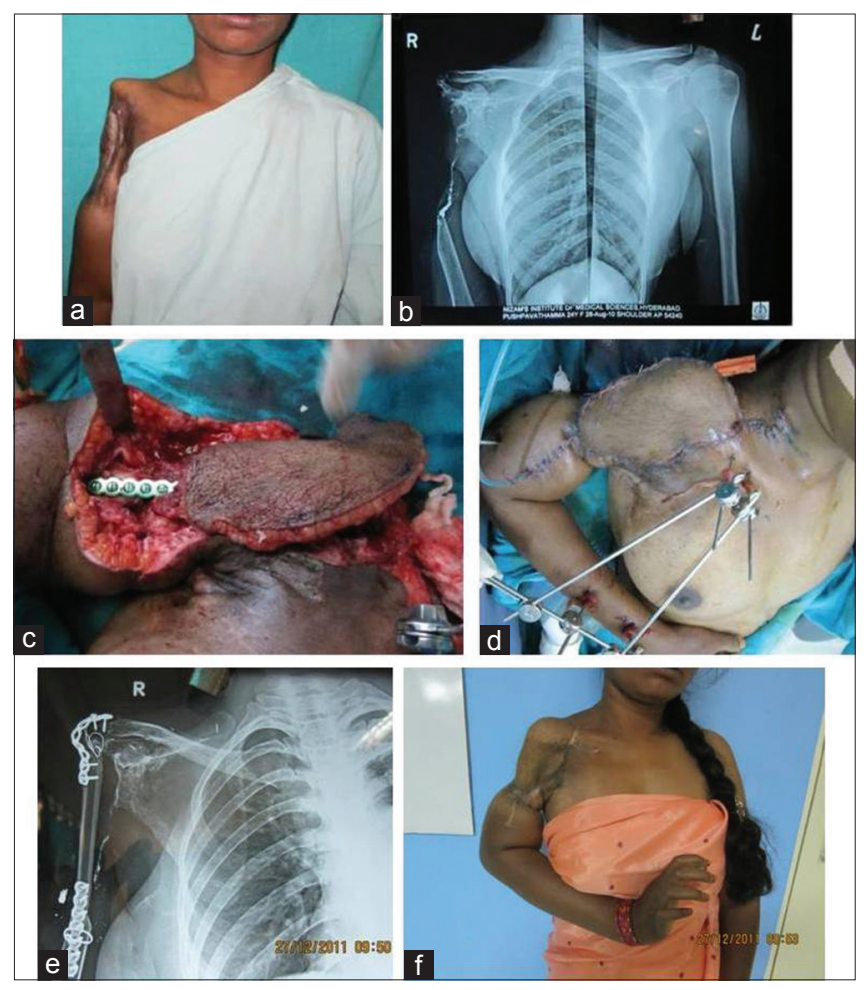

Figure 7: Proximal humerus reconstruction using free fibula osteocutaneous flap. (a) Post-resection and radiotherapy for Ewing's sarcoma involving head and proximal shaft humerus, (b) X-ray showing the bone loss, (c and d) Intraoperative stabilisation of fibula with the humerus, (e and f) follow-up pictures

vessels for head-and-neck reconstructions as they are spared during previous neck dissections and less likely to be affected by standard irradiation protocols. ${ }^{.20]}$ These vessels are reliable and robust and can reduce the need for vein grafts. It has a comparable diameter and blood flow, as the other branches of the ECA ${ }^{[21]}$ and less affected by atherosclerosis than the carotid system. ${ }^{[17]}$

Due to its location, these vessels can also be used to advantage for the upper arm and the proximal thoracic reconstructions if the native first choice vessels are not available.

The concern with the transverse cervical vessels seems to be the size of the vessels, venae commitantes and positioning the pedicle especially for proximal chest and upper arm reconstructions. These concerns can be attended as follows.

For reconstructions at the lateral chest or the upper limb, the orientation of the vessels is more or less in line with the area of reconstruction; hence, minor realignment of the of pedicle is sufficient (30-45 );

Indian Journal of Plastic Surgery Volume 51 Issue 2 May-August 2018 
Reconstruction of the medial chest needs more angulations of the pedicle, up to $90^{\circ}$ or more. Pedicle can be pivoted up to $90^{\circ}$ where the donor pedicle length is limited. If $>90^{\circ}$ angulation is needed, donor pedicle was arced up to prevent any kink at the site of the anastomiosis.

All these reconstructions sustained the realignment well without any risk of kink.

Well-supported anastomoses over the underlying muscular bed (unlike the facial vessels in submandibular region), and the excellent blood flow thrusting on the vessel wall probably would have helped in maintaining the smooth arc avoiding the risk of kink.

Post-operatively, immobilisation with the neck in extension and chin turned to the opposite side may prevent compression of the venous anastomosis.

Prior dissection of the EJV ensures safe drainage even in case of variable venous anatomy of TCvTransverse cervical vein.

Although the origin of the TCa may vary $(77 \%$ from the thyrocervical trunk; $21 \%$ directly from the subclavian artery or from the internal mammary artery $\left.2{ }^{2}{ }^{[22]}\right)$, the TCa was seen in all 14 cases. Out of 13, 12 times the transverse cervical artery used for the anastomosis was deemed a success at the end of the surgery; in one case, the anastomosis had to be redone to the superior thyroid artery on table, and one TCa could not be used at all.

The transverse cervical vein might have a variable course, running deep (75\%), or superficial (25\%) to the omohyoid. It could drain into the EJV or the subclavian vein. ${ }^{[23]}$ Five venae commitantes were used in this series. In only 2 of 12 cases, we relied on the venae commitantes alone. The EJV was always present. However, in one case of hemifacial hypoplasia, EJV was hypoplastic and rerouted cephalic vein was used.

Although the dissection of the transverse cervical artery is fairly straightforward, it is not devoid of risk. The phrenic nerve lies in the region of the transverse cervical artery branching from the thyrocervical trunk; on the left, the thoracic duct courses anterior to the transverse cervical artery near its branching point from the thyrocervical trunk. ${ }^{[21]}$ Neither of these structures (Phrenic nerve or Thoracic duct) suffered any injury in the present series.

\section{Favourable factors to choose the TCV as second-line recipient vessels}

1. Constant location of the vessels in an untouched and unirradiated area

2. Easily accessible, dissectible in the superficial fat planes, in a short time of about $20-30 \mathrm{~min}$

3. Arterial diameter is $>2 \mathrm{~mm}$ for a safe anastomosis without much mismatch

4. Usable length of $2-4 \mathrm{~cm}$ allows for an adequate realignment of the pedicle if needed, for a comfortable anastomosis

5. Favourable orientation of vessels over an even bed of scalene muscles for head-and-neck reconstructions. Reliable realignment of the pedicle for the upper limb and trunk reconstructions Further, donor pedicle can be tunnelled subcutaneously without opening up the neck skin for flaps with adequate pedicle lenth $^{[24]}$

6. Advantageous location in the lower neck away from the mandible and clavicle allows easy positioning of the microscope thus a comfortable anastomosis

7. In the absence of appropriate sized veins, EJV is the best alternate choice available in the vicinity for venous drainage.

All these factors with few simple careful measures helped us in locating the anastomosis at a favourable depth away from the potentially diseased or injured recipient sites and avoiding a compromised anastomosis or a difficult end-to-side anastomosis to axial vessels in a deeper plane thus aiding a favourable outcome of these unusual reconstructions in difficult situations.

Thus, we consider the transverse cervical vessels as a safe second-line choice for the extended use in the upper arm and trunk reconstructions in addition to head-and-neck reconstructions.

\section{CONCLUSIONS}

Transverse cervical vascular pedicle is a safe option as a second-line recipient vessel in difficult head-and-neck reconstructions; in addition, they are useful as the recipient vessel in thoracic and proximal upper limb reconstructions. Preserving the EJV during dissection ensures safe venous drainage, even when the accompanying vein is of small calibre. Care needs to be exercised regarding choosing the transverse cervical vessels in the presence of severe hemifacial atrophy. 


\section{Declaration of patient consent}

The authors certify that they have obtained all appropriate patient consent forms. In the form, the patient has given her consent for her images and other clinical information to be reported in the journal. The patient understand that names and initials will not be published and due efforts will be made to conceal identity, but anonymity cannot be guaranteed.

\section{Financial support and sponsorship}

Nil.

\section{Conflicts of interest}

There are no conflicts interest.

\section{REFERENCES}

1. Head C, Sercarz JA, Abemayor E, Calcaterra TC, Rawnsley JD, Blackwell KE, et al. Microvascular reconstruction after previous neck dissection. Arch Otolaryngol Head Neck Surg 2002;128:328-31.

2. Schusterman MA, Miller MJ, Reece GP, Kroll SS, Marchi M, Goepfert $\mathrm{H}$, et al. A single center's experience with 308 free flaps for repair of head and neck cancer defects. Plast Reconstr Surg 1994;93:472-8

3. Nakayama B, Kamei Y, Toriyama K, Hyodo I, Hasegawa Y, Torii S, et al. Usefulness of a first transferred free flap vascular pedicle for secondary microvascular reconstruction in the head and neck. Plast Reconstr Surg 2002;109:1246-53.

4. Yazar S, Wei FC, Chen HC, Cheng MH, Huang WC, Lin CH, et al. Selection of recipient vessels in double free-flap reconstruction of composite head and neck defects. Plast Reconstr Surg 2005;115:1553-61.

5. Mulholland S, Boyd JB, McCabe S, Gullane P, Rotstein L, Brown D, et al. Recipient vessels in head and neck microsurgery: Radiation effect and vessel access. Plast Reconstr Surg 1993;92:628-32.

6. Bengtson BP, Schusterman MA, Baldwin BJ, Miller MJ, Reece GP, Kroll SS, et al. Influence of prior radiotherapy on the development of postoperative complications and success of free tissue transfers in head and neck cancer reconstruction. Am J Surg 1993;166:326-30.

7. Aitasalo K, Relander M, Virolainen E. Microvascular free tissue transfers after preoperative irradiation in head and neck reconstructions. Acta Otolaryngol Suppl 1997;529:247-50.

8. Jose B, Banis J, Flynn M, Lindberg R, Spanos WJ Jr., Paris K, et al. Irradiation and free tissue transfer in head and neck cancer. Head Neck 1991;13:213-6.

9. Wei FC, Demirkan F, Chen HC, Chuang DC, Chen SH, Lin CH, et al. The outcome of failed free flaps in head and neck and extremity reconstruction: What is next in the reconstructive ladder? Plast Reconstr Surg 2001;108:1154-60.

10. Urken ML, Weinberg $\mathrm{H}$, Buchbinder D, Moscoso JF, Lawson W, Catalano PJ, et al. Microvascular free flaps in head and neck reconstruction. Report of 200 cases and review of complications. Arch Otolaryngol Head Neck Surg 1994;120:633-40.

11. Hidalgo DA, Disa JJ, Cordeiro PG, Hu QY. A review of 716 consecutive free flaps for oncologic surgical defects: Refinement in donor-site selection and technique. Plast Reconstr Surg 1998;102:722-32.

12. Zhang F, Ho PR, Chin BT, Ozek C, Buncke HJ, Lineaweaver WC, et al. Effect of vein grafting on the survival of microvascularly transplanted muscle flaps. Microsurgery 1996;17:512-6.

13. Miller MJ, Schusterman MA, Reece GP, Kroll SS. Interposition vein grafting in head and neck reconstructive microsurgery. J Reconstr Microsurg 1993;9:245-51.

14. Germann G, Steinau HU. The clinical reliability of vein grafts in free-flap transfer. J Reconstr Microsurg 1996;12:11-7.

15. Albertengo JB, Rodriguez $A$, Buncke $H J$, Hall EJ. A comparative study of flap survival rates in end-to-end and end-to-side microvascular anastomosis. Plast Reconstr Surg 1981;67:194-9.

16. Chia HL, Wong $\mathrm{CH}$, Tan BK, Tan KC, Ong YS. An algorithm for recipient vessel selection in microsurgical head and neck reconstruction. J Reconstr Microsurg 2011;27:47-56.

17. Urken ML, Vickery C, Weinberg H, Buchbinder D, Biller HF. Geometry of the vascular pedicle in free tissue transfers to the head and neck. Arch Otolaryngol Head Neck Surg 1989;115:954-60.

18. Cheng HT, Lin FY, Chang SC. Evidence-based analysis of vein graft interposition in head and neck free flap reconstruction. Plast Reconstr Surg 2012;129:853e-4e.

19. Furr MC, Cannady S, Wax MK. Interposition vein grafts in microvascular head and neck reconstruction. Laryngoscope 2011;121:707-11.

20. Yu P. The transverse cervical vessels as recipient vessels for previously treated head and neck cancer patients. Plast Reconstr Surg 2005;115:1253-8.

21. Xu ZF, Duan WY, Zhang EJ, Bai S, Tian $Y$, Tan $X X$, et al. Transverse cervical vessels as recipient vessels in oral and maxillofacial microsurgical reconstruction after former operations with or without radiotherapy. World J Surg Oncol 2015;13:183.

22. Huelke DF. A study of the transverse cervical and dorsal scapular arteries. Anat Rec 1958;132:233-45.

23. Daseler $\mathrm{EH}$, Anson BJ. Surgical anatomy of the subclavian artery and its branches. Surg Gynecol Obstet 1959;108:149-74.

24. Tessler O, Gilardino MS, Bartow MJ, St Hilaire H, Womac D, Dionisopoulos $\mathrm{T}$, et al. Transverse cervical artery: Consistent anatomical landmarks and clinical experience with its use as a recipient artery in complex head and neck reconstruction. Plast Reconstr Surg 2017;139:745e-51e. 